Article

\title{
Experimental Study on the Relationship between the Velocity of Surface Movements and Tilting Rate in Pre-Failure Stage of Rainfall-Induced Landslides
}

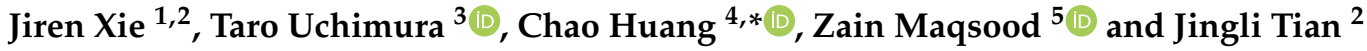 \\ 1 Institute of Geographic Sciences and Natural Resources Research, Chinese Academy of Sciences, \\ Beijing 100101, China; jirenxie198911@csu.edu.cn \\ 2 Department of Civil Engineering, Central South University, Changsha 410075, China; tianjingli@csu.edu.cn \\ 3 Department of Civil and Environmental Engineering, Saitama University, 255 Shimo-Okubo, Sakura-ku, \\ Saitama 338-8570, Japan; uchimurataro@mail.saitama-u.ac.jp \\ 4 Disaster Prevention Research Institute, Kyoto University, Uji, Kyoto 611-0011, Japan \\ 5 School of Civil and Environmental Engineering, National University of Sciences and Technology, H-12, \\ Islamabad 44000, Pakistan; zmaqsood@nice.nust.edu.pk \\ * Correspondence: huangchao10@foxmail.com
}

\section{check for} updates

Citation: Xie, J.; Uchimura, T.; Huang, C.; Maqsood, Z.; Tian, J. Experimental Study on the Relationship between the Velocity of Surface Movements and Tilting Rate in Pre-Failure Stage of Rainfall-Induced Landslides. Sensors 2021, 21, 5988. https://doi.org/ $10.3390 / \mathrm{s} 21185988$

Academic Editor:

Domenico Calcaterra

Received: 14 July 2021

Accepted: 2 September 2021

Published: 7 September 2021

Publisher's Note: MDPI stays neutral with regard to jurisdictional claims in published maps and institutional affiliations.

Copyright: (c) 2021 by the authors. Licensee MDPI, Basel, Switzerland. This article is an open access article distributed under the terms and conditions of the Creative Commons Attribution (CC BY) license (https:/ / creativecommons.org/licenses/by/ $4.0 /)$.

\begin{abstract}
With the development of deformation measuring technology at slope surfaces, prediction methods for rainfall-induced landslides based on the surface movements and tilting of slopes in the pre-failure stage have been recognized as a promising technique for risk reduction of slope failure triggered by rainfall. However, the correlation and possible mechanism for these prediction methods were rarely discussed. In this study, the comparison between the prediction methods of slope failure based on the time history of surface displacements and tilting in the acceleration stage was carried out by conducting a series of laboratory tests and field tests under rainfall, in which the movements and tilting behaviors at the slope surface were measured. The results show that the predicted failure time of tested slopes obtained by different prediction methods is consistent, and the correlation between these landslide prediction methods were also detected. A proportional relationship between the velocity of surface displacements and tilting rate was observed, and a possible mechanism for the sliding behavior was discussed based on this linear relationship as well. In addition, an expression for the linear relationship between the rate of the surface tilting and displacement was also established in this study, and the results could have significance for the understanding of the sliding behavior in the failure process in rainfall-induced landslides.
\end{abstract}

Keywords: rainfall-induced landslides; tilting rate; velocity of surface displacements; laboratory tests and field tests; linear relationship; prediction

\section{Introduction}

Rainfall-induced landsides often lead to serious damage on environment, infrastructures, and human lives. It was reported that the rainfall-induced landslides cause thousands of fatalities and billions of dollars in economic losses every year [1-5].

Longstanding effort has been made to mitigate the risk of damages caused by rainfallinduced landslides, which was recognized as a difficult task due to many influential factors, such as rainfall, geotechnical properties of soils on slopes, or the ground water level and so on. Traditional methods for landslide damage reduction, such as retaining walls and piles, improve the factor of safety by mechanical reinforcement measures. These methods are costly and not suitable for a large number of slopes with potential risks of failure.

In recent decades, early warning methods of rainfall-induced landslides with low cost and negligible environmental impact have been proposed and recognized as promising approaches for the risk reduction of landslide disasters. These methods are used to detect the pre-failure behavior of landslides triggered by rainfall and evacuate the residents living 
in the landslide prone in a timely manner [6-10]. Centrifuge and mechanics-based models were used to study and assess rainfall-induced instabilities in different slopes [11,12], and climate change increasing the amount of antecedent rainfall significantly affects the rainfall-induced landslide vulnerability of the area [13].

Many landslide prediction methods were proposed based on the soil moisture measurement [14,15] and local rainfall record [16-18]. These methods are not effective to evaluate the risk of the slope failure due to the unclear correlation between the soil moisture content or precipitation and the occurrence of landslides. The typical landslide prediction methods were derived from the surface displacement, and many empirical equations using derivatives of surface displacements were also developed to estimate the slope failure time [19-21]. A general form of these empirical equations were firstly given by Fukuzono expressed as Equation (1) [22,23]. However, the mechanism of these typical landslide prediction methods is still unclear.

$$
\frac{d t}{d s}=[A \cdot(\alpha-1)]^{\frac{1}{\alpha-1}}\left(t_{f}-t\right)^{\frac{1}{\alpha-1}}
$$

where $\frac{d t}{d s}$ denotes reciprocal displacement rate. $A$ and $\alpha$ are constant parameters. $t$ represents the time, and $t_{f}$ means the slope failure time at which the displacement rate becomes infinitely large. It was reported that the value of $\alpha$ is close to 2 [23-27], so the above equation can be rewritten as

$$
\frac{d t}{d s}=A \times\left(t_{f}-t\right)
$$

Additionally, a new landslide prediction method based on the surface tilting was proposed by Xie [28]. This method adopts the following equation to forecast the slope failure time

$$
\frac{d t}{|d \theta|}=\frac{1}{B} \times\left(t_{F}-t\right)
$$

where $\frac{d t}{d \theta}$ is the inverse number of the tilting rate, and $B$ is a constant parameter, while $t$ means the time and $t_{F}$ represents the slope failure time when the reciprocal tilting rate becomes $0 \mathrm{~min} /{ }^{\circ}$. As shown in Equations (2) and (3), the formula of landslide predicting methods based on the time history of surface displacements and tilting are analogue, which indicate that the reciprocal velocity of surface deformation including displacements and tilt angles reveals a linear relationship with the duration before the slope failure. However, limited studies were carried to investigate the mechanism of the similarity between these methods, and the correlation between the deformation indexes used in different prediction methods.

In this paper, a comparison between the landslide prediction methods using the surface tilting and displacements was studied by performing a series of model tests at both laboratory and field scales, in which extensometers and tilt sensors were used for the measurement of surface movements and tilt angles. The relationship between the tilting rate and displacement rate was also investigated and validated.

\section{Methods and Materials}

To investigate the correlation between the landslide predicting methods based on the surface tilting and displacements of slopes, a series of laboratory model tests and field tests were carried out.

\subsection{Laboratory Model Tests}

Two small flume tests were performed. In Model Test 1, the slope model was made in a rectangular container with the size of $1165 \mathrm{~mm}$ (length) $\times 450 \mathrm{~mm}$ (width) $\times 380 \mathrm{~mm}$ (height), and composed of two layers with different dry density using silica sand number 7 . The particle size distribution of the materials is presented in Figure 1, and the specific gravity of soil solids $\left(G_{s}\right)$ is 2.63 . The dry density of the base layer is $1.60 \mathrm{~g} / \mathrm{cm}^{3}$ with the 
void ratio of 0.64 , while the dry density of the surface layer is $1.32 \mathrm{~g} / \mathrm{cm}^{3}$, of which the void ration is around 1 .

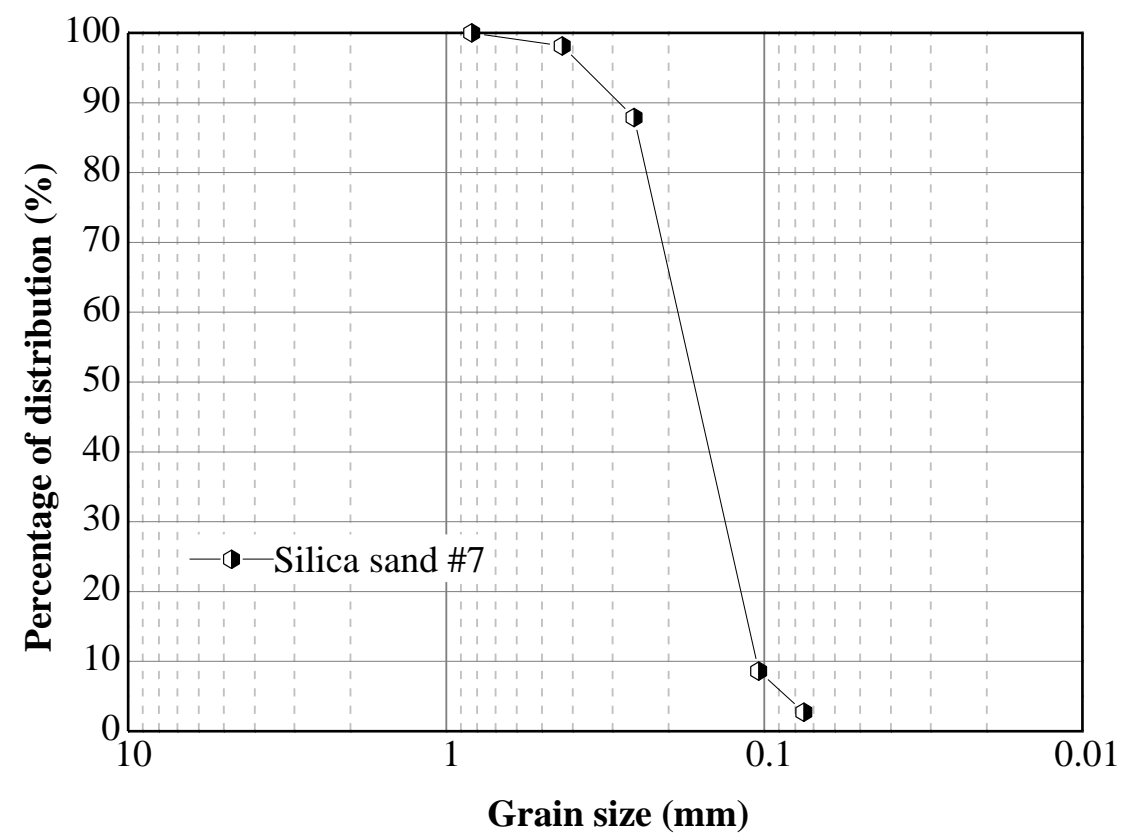

Figure 1. Particle size distribution of silica sand number 7.

The slope model composed of two different layers with specified densities was built by tamping, and the initial moisture content is $10 \%$. A pre-designed irregular circular slip surface with different radiuses was set between these two layers as shown in Figure 2. The radius of the slip surface of the upper part was $300 \mathrm{~mm}$, and it was $800 \mathrm{~mm}$ in the lower part. After making the slope model at horizontal position, this slope model was inclined to a target angle about 40 degrees before artificial rainfall with the rainfall intensity of $70 \mathrm{~mm} / \mathrm{h}$ applied. The intensity of artificial rainfall was controlled by a rainfall system, which was composed of a nozzle, a water tank and an air pressure cylinder. Two tilt sensors and extensometers which are noted by " $\mathrm{T}$ " and " $\mathrm{E}$ " were exploited in this test with the accuracy of 0.1 degree and $0.1 \mathrm{~mm}$ to measure the pre-failure tilting behavior and the surface displacement of the slope as indicated in Figure 2.

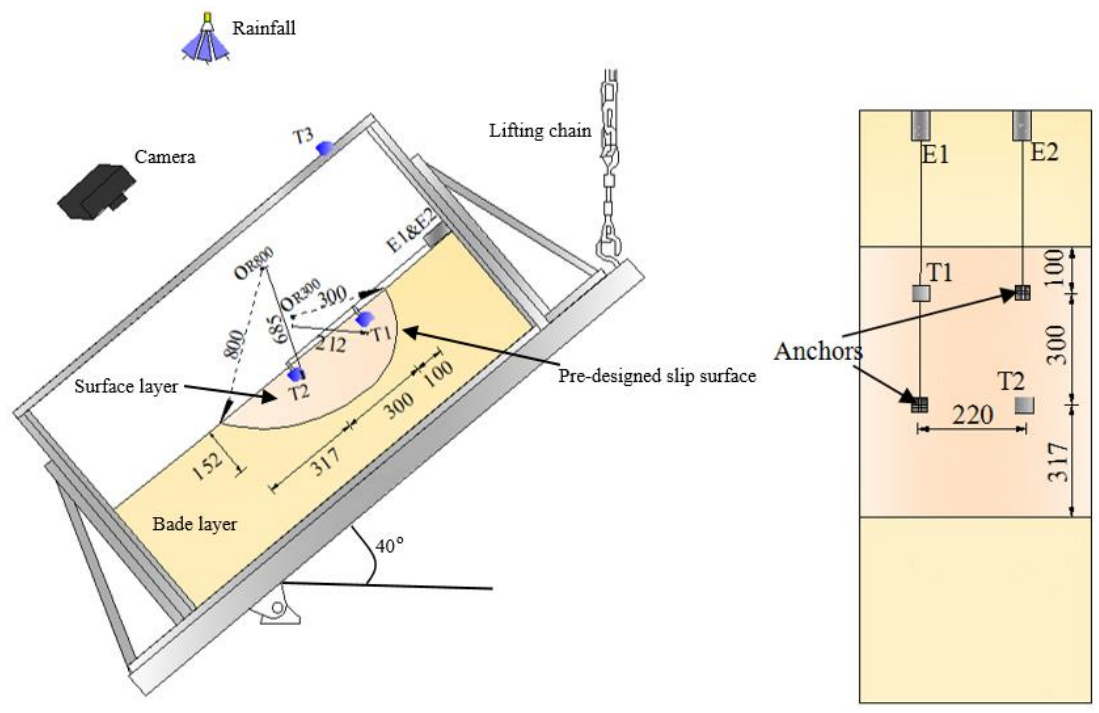

Figure 2. Illustration of the arrangement of instruments in Model Test 1. 
In Model Test 2, the slope model was also made of silica sand number 7, and the dry density of the slope is $1.32 \mathrm{~g} / \mathrm{cm}^{3}$ with an initial moisture of $10 \%$. The slope dimension of this model is shown in Figure 3. Nine marked points using wooden sticks of $5 \mathrm{~cm}$ were set in the slope close to the location where tilt sensors were installed. A digital camera parallel to the slope profile was used to record the movement of marked points in the slope based on the image technique, while the slope tilting behavior was measured by the tilt sensors. The slope model in this test was also built horizontally, and then inclined gradually to a specific angle of 15 degree using the lifting mechanism as shown in Figure 3 before the artificial rainfall with a constant intensity of $50 \mathrm{~mm} / \mathrm{h}$ applied. In this test, nine tilt sensors with the accuracy of 0.1 degree were used, and behaviors in the first slope failure occurred at the toe of the slope was captured by the tilt sensor 1 (T1) and marked point 1 (M1).

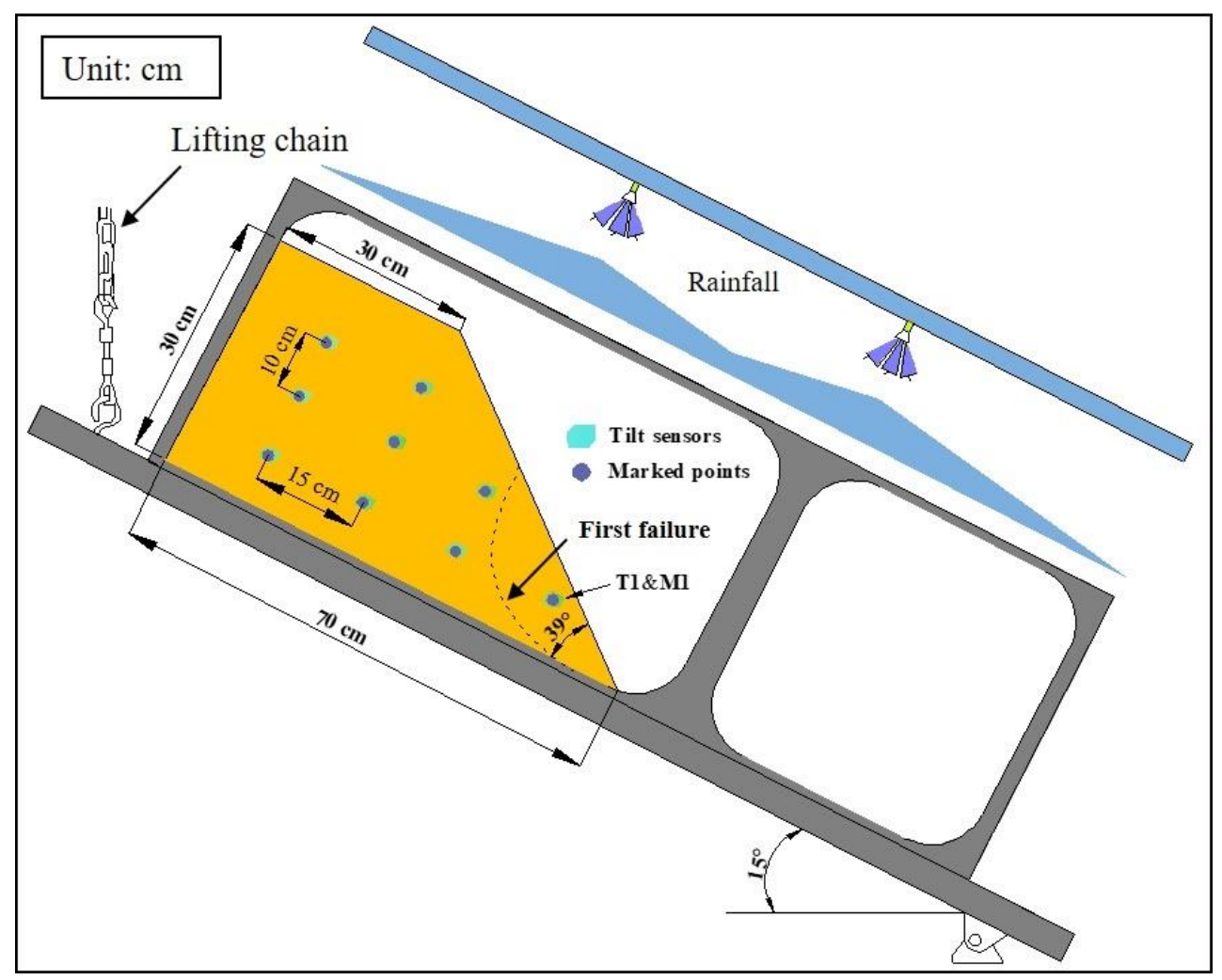

Figure 3. Illustration of the arrangement of instruments in Model Test 2.

\subsection{Field Tests}

Two field tests were performed on natural slopes in Baise city of Guangxi province where the weakly expansive clay is widely distributed. The chosen site, located in westernnorthwestern Guangxi, has a humid subtropical climate. Rainfall is relatively low compared to eastern locations in Guangxi, averaging around $1000 \mathrm{~mm}$ per annum, a majority of which occurs from June to August. The western parts of location, with an average elevation surpassing $500 \mathrm{~m}$, lie along the southeastern fringes of the Yunnan-Guizhou Plateau. The area is the prone and frequent occurring areas of geological hazards including landslides and debris flow.

Particle size distribution of the in-situ soil is presented in Figure 4. The angle of these test slopes was around 40 degrees, and a trench was excavated at the toe of the slope with a depth of $0.2 \mathrm{~m}$ to make the slope easier to collapse. In Field Test 1 , six tilt sensors and three extensometers were exploited to monitor the slope surface deformation, and the experimental setup is indicated in Figure $5 \mathrm{a}$,c. The three extensometers were attached to the tilt sensors T1, T2, and T3 which were located at the bottom area. After the installation of tilt sensors, artificial rainfall was applied with a constant rainfall intensity of $21 \mathrm{~mm} / \mathrm{h}$ using the rainfall supply system which was composed of six nozzles, a pump, and several tubes. 


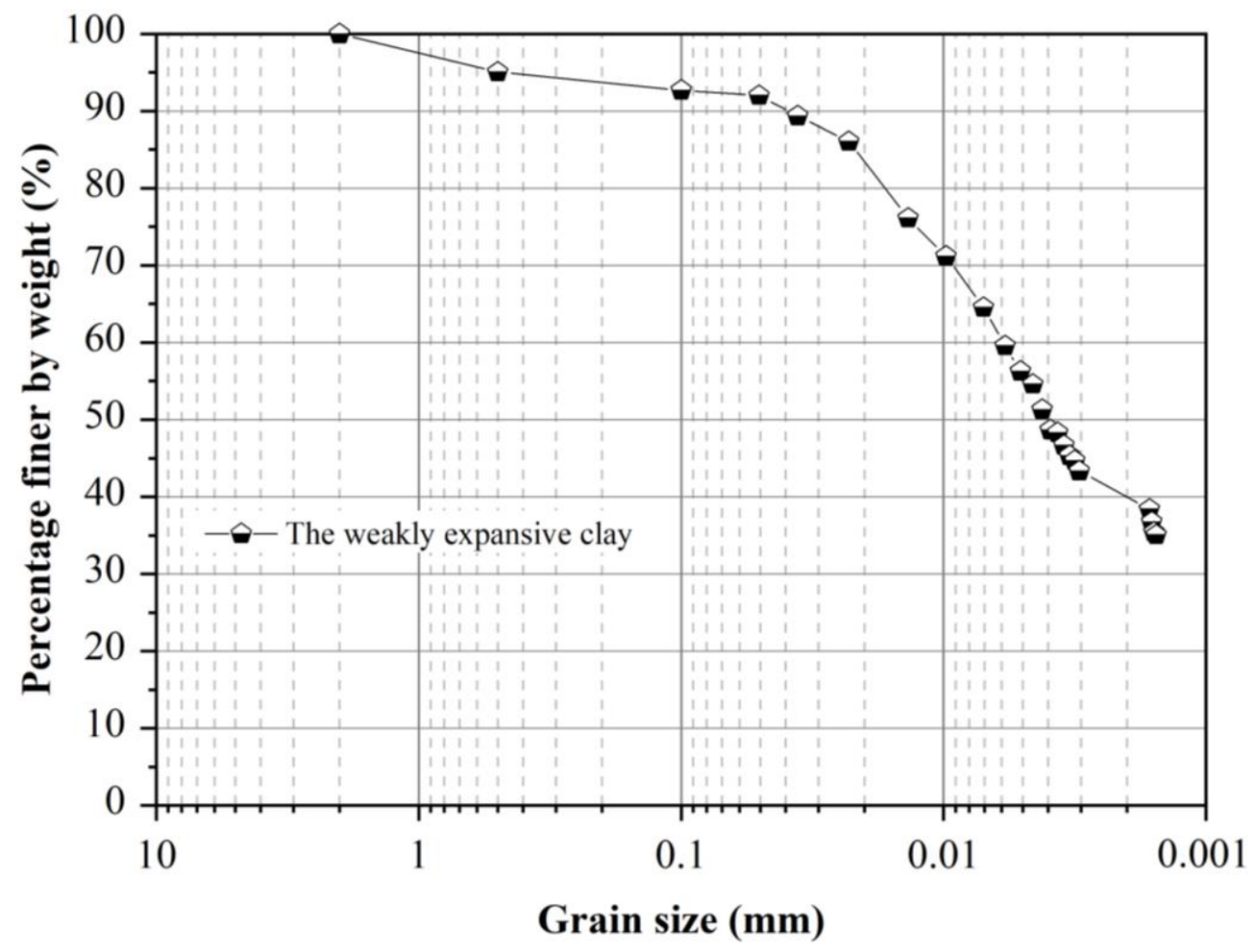

Figure 4. Particle size distribution of the soil in field tests.
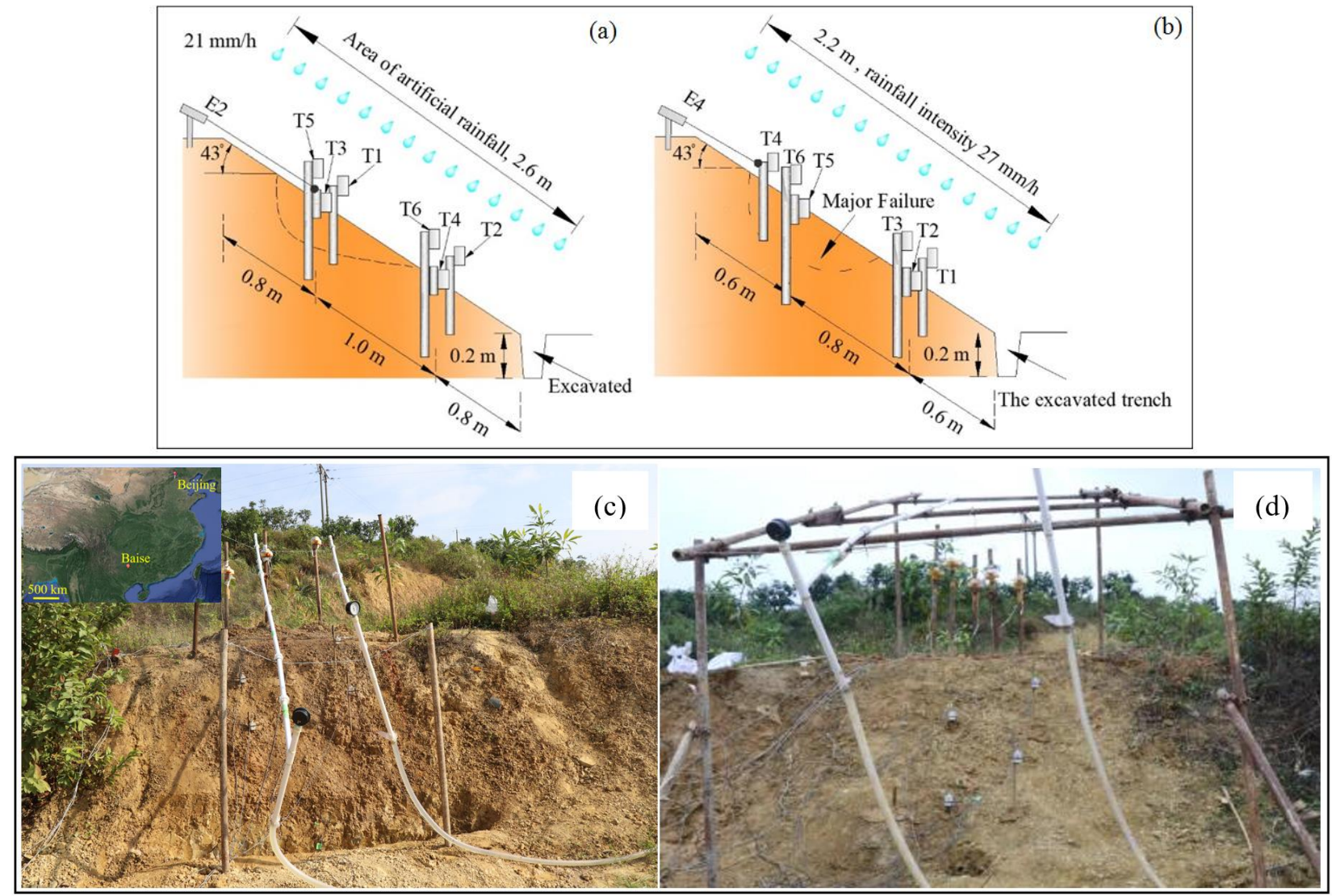

Figure 5. Cont. 


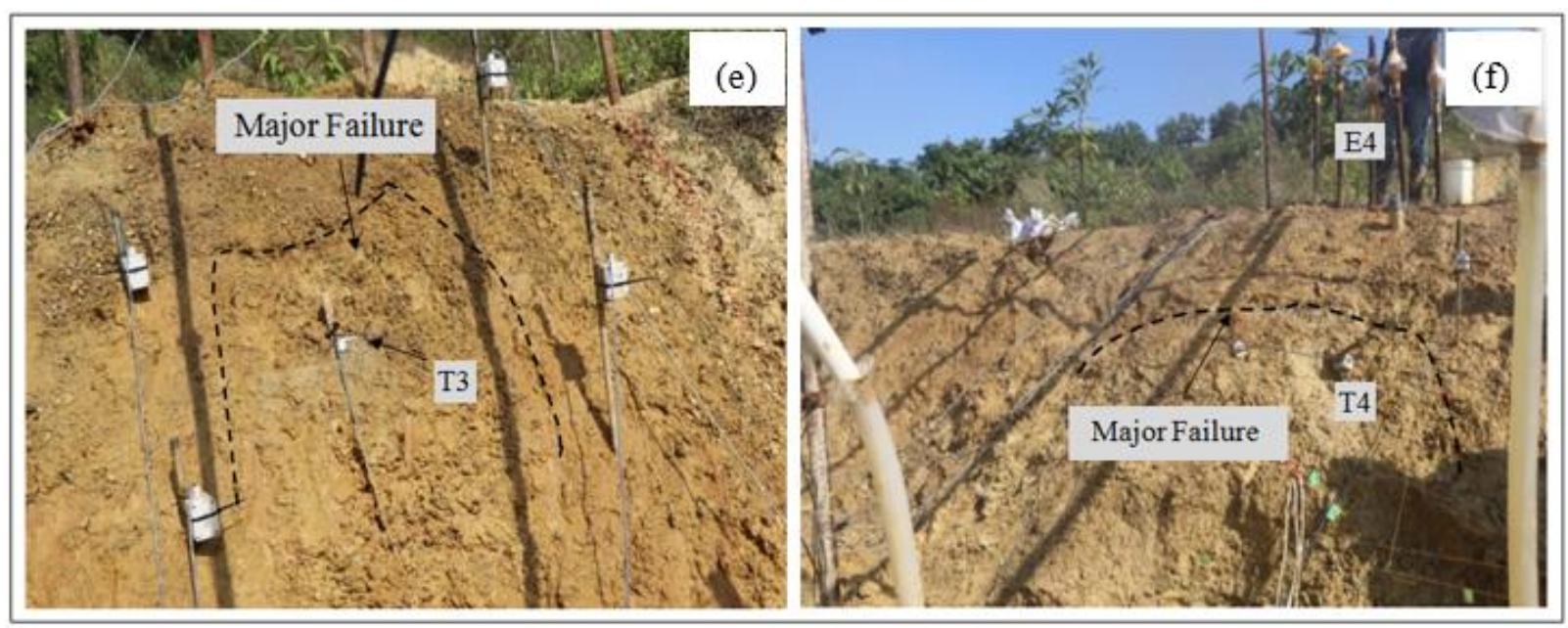

Figure 5. (a) The arrangement of instruments in Field Test $1 ;$ (b) The arrangement of instruments in Field Test 2; (c) The test slope in field test $1 ;(\mathbf{d})$ The test slope in Field Test 2; (e) The major failed part of the test slope in Field Test 1; (f) The major failed part of the test slope in Field Test 2. Tilt sensors and extensometers which are noted by " $\mathrm{T}$ " and " $\mathrm{E}$ " were exploited in this test.

The major failure occurred in the middle part of the slope four hours later as shown in Figure 5e. Compared with the test conditions in Field Test 1, six extensometers together with tilt sensors were used in this field test, and a slight different rainfall intensity of $27 \mathrm{~mm} / \mathrm{h}$ was applied in Field Test 2. The arrangement of apparatus in the test as shown in Figure 5b,d. Similarly, the major failure was also occurred in the middle part of the slope revealed in Figure 5f, and the pre-failure behavior of the slope surface was recorded by the extensometer, E4 as well as the tilt sensor, T4.

\section{Test Results and Discussion}

\subsection{Results of Model Test 1}

In this test, the slope failure was triggered by applying artificial rainfall with constant rainfall intensity of $70 \mathrm{~mm} / \mathrm{h}$, and the slope slid along the pre-designed slip surface. The pre-failure tilting behavior and displacement of the slope surface were detected by the tilt sensors and extensometers as shown in Figure 2. Time series of surface displacements and tilting angles measured by the extensometers and tilt sensors are presented in Figure 6a,b respectively. An accelerating stage of surface deformation before the slope failure is shown in these figures.
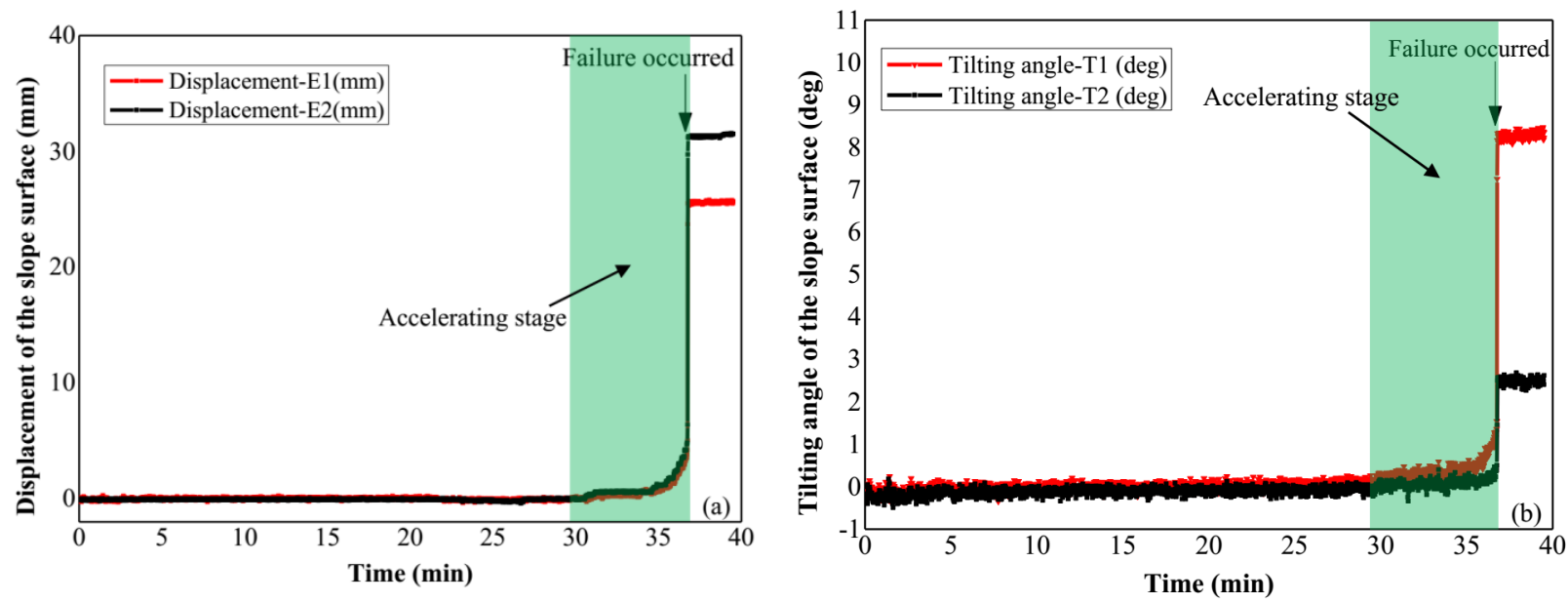

Figure 6. (a) Time history of the displacement at the slope surface in Model Test 1, (b) time series of the tilting angle at the slope surface. 
In addition, the relationship between reciprocal rates of surface deformation and the time is presented in Figures 7 and 8, which is based on the time history of surface displacement and tilting respectively. The method for the calculation of the reciprocal rate of surface deformation is provided in Appendix A of this paper. The failure time of the slope forecasted using Equation (2) based on the linear trends revealed in Figure 7 is close to $36.7 \mathrm{~min}$. Moreover, the predicted slope failure time was obtained using Equation (3) according to the relationship between the reciprocal tilting rate and time indicated in Figure 8, which also approximates to the real failure time, $36.7 \mathrm{~min}$. The results reveal that consistent predicted failure time of slopes can be achieved using the typical landslide forecasting method based on the surface displacement and the new prediction method proposed by authors derived from the slope surface tilting.

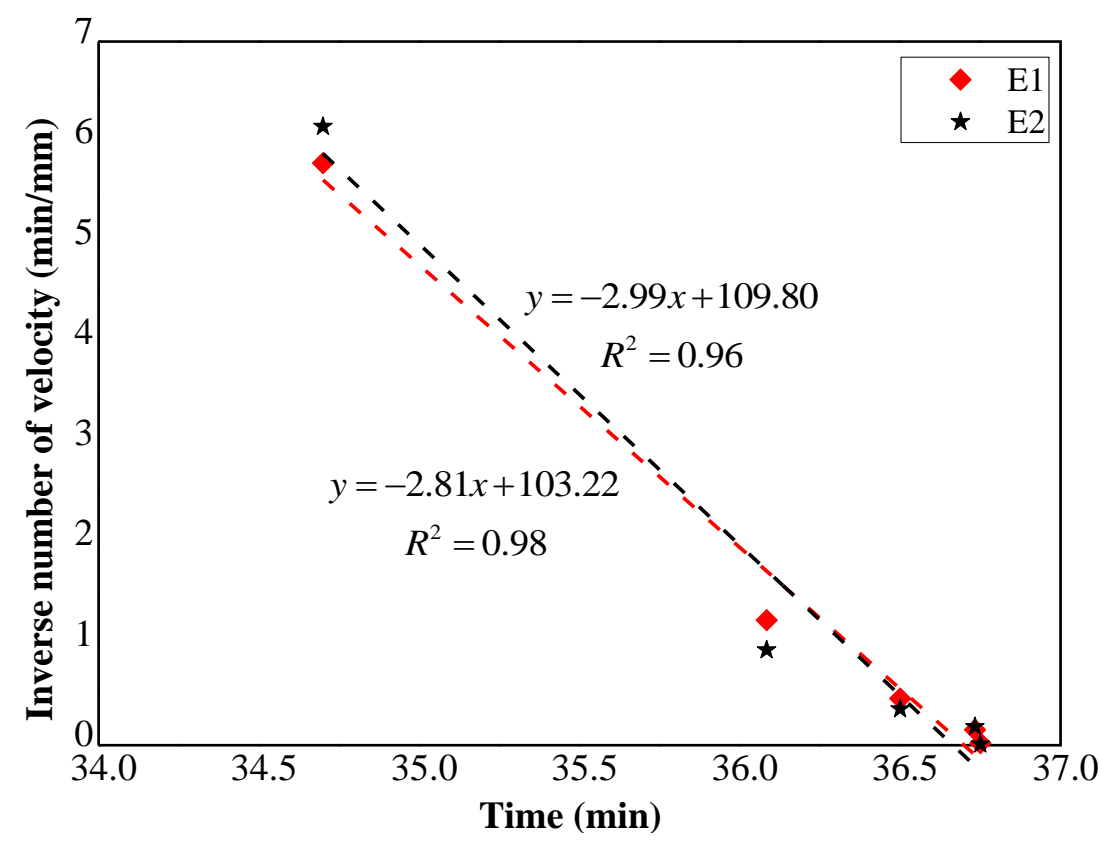

Figure 7. Time series of the reciprocal displacement rate of E1 and E2.

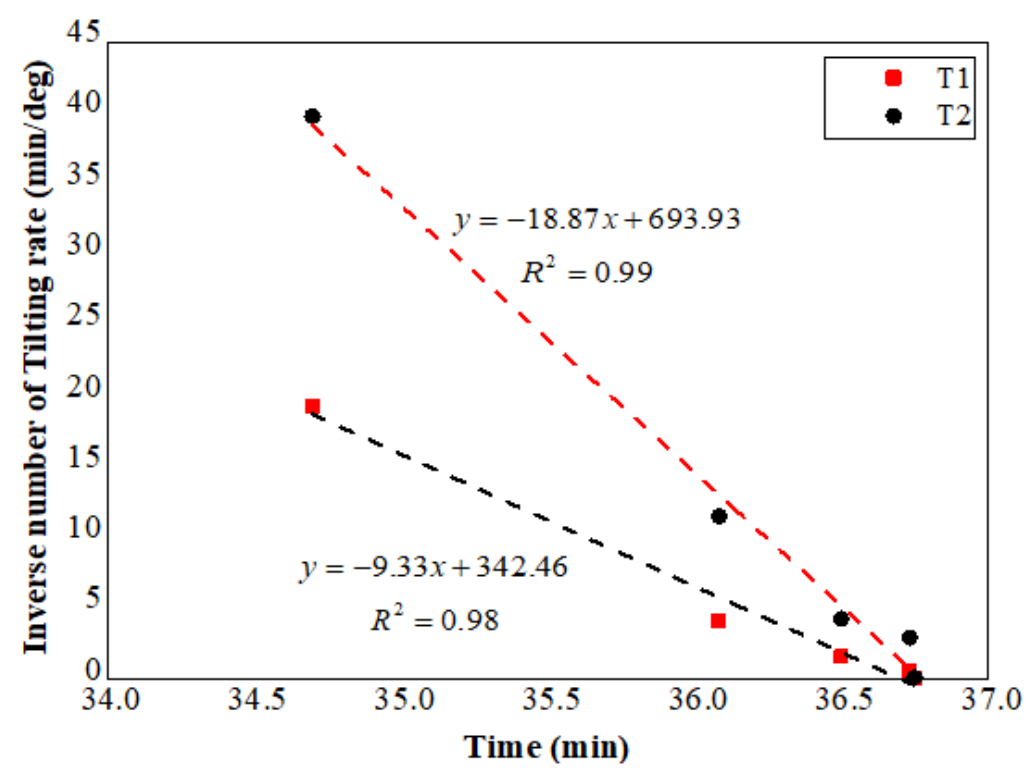

Figure 8. Time series of the reciprocal tilting rate of $\mathrm{T} 1$ and $\mathrm{T} 2$. 


\subsection{Results of Model Test 2}

Compared with Model Test 1 , the slope failure of this test was also induced by applying artificial rainfall with a constant rainfall intensity, which was $50 \mathrm{~mm} / \mathrm{h}$. The slope failure began at the toe of the slope before the second failure occurred. The displacement of the slope in the first failure presented in Figure 9a was derived from the movement of the marked point set in the failed part using the image analysis technique. Corresponding tilting behaviors of the failure part was recorded by the tilt sensor located in this region is presented in Figure 9b. An accelerating stage of the surface deformation including displacements and tilting angles before the slope failure is revealed in time history of the surface displacement and tilting.
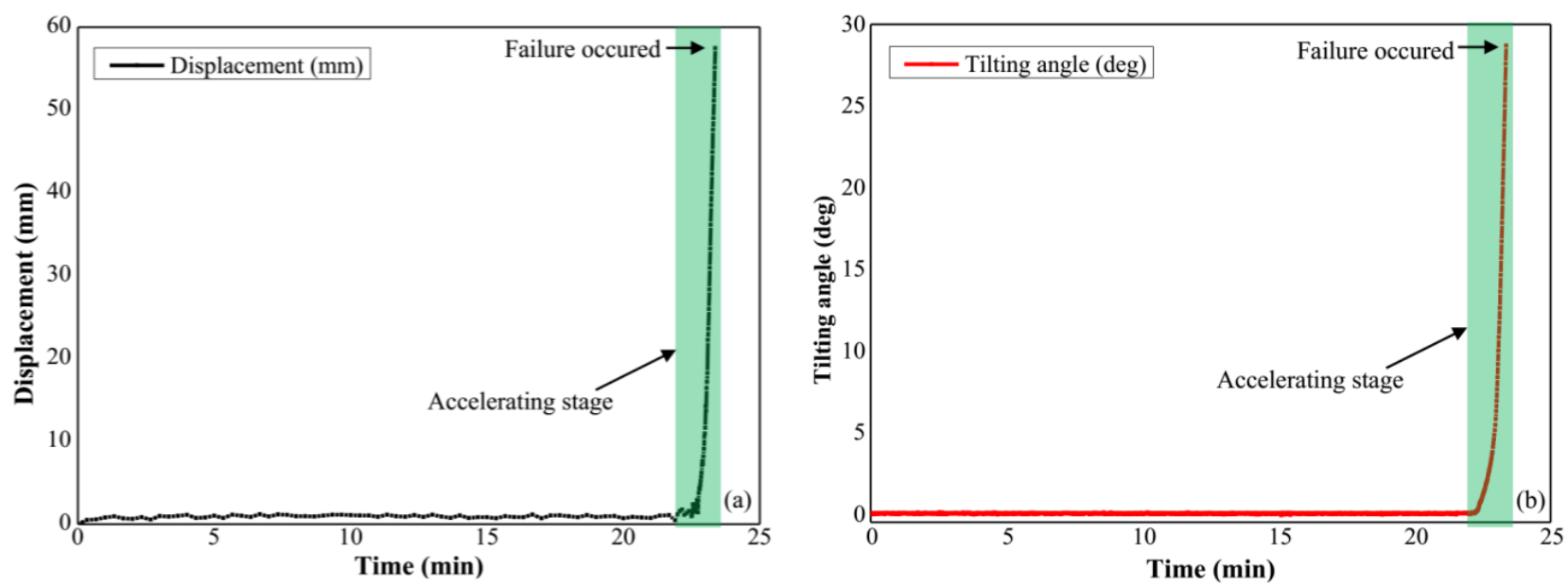

Figure 9. (a) Time history of the displacement at subsurface in Model Test 2, (b) time series of the tilting angle at the subsurface in Model Test 2.

The correlation between inverse number of displacement rate and time in the acceleration stage is presented in indicated in Figure 10a, while the relationship between the reciprocal tilting rates and time is shown in Figure 10b. Linear relations between the reciprocal rate of displacements and tilting angles against time are presented in Figure 10a,b, and the fitting lines for these linear relations are also presented in these figures. The predicted slope failure time was computed using Equations (2) and (3) based on the fitting lines as shown in Figure 10, and a consistent result was obtained, which is $23.12 \mathrm{~min}$ approximating to the real failure time.
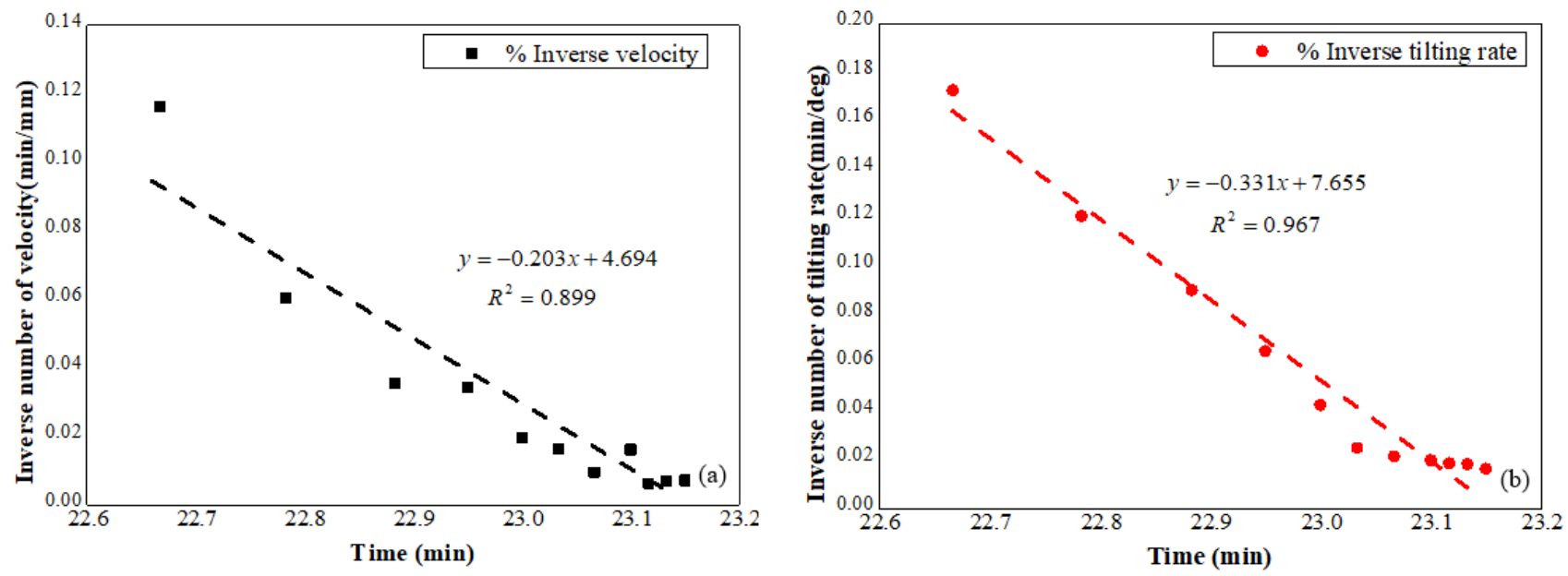

Figure 10. (a) Reciprocal displacement rate against time, (b) reciprocal tilting rate against time. 


\subsection{Results of Field Test 1}

The slope failure in Field Test 1 was caused by applying artificial rainfall with the rainfall intensity of $21 \mathrm{~mm} / \mathrm{h}$. The major failure occurred in the middle part of the slope where tilt sensor T3 and the extensometer E2 located. The failed part slid along the slip surface with a depth of $23 \mathrm{~cm}$, and the cumulative displacement and tilting angle measured by E2 and T3 are provided in Figure 11. A similar trend between the surface displacement and tilting angle against time is indicated in these figures, and the accelerating behavior is also observed both in the time history of surface displacements and tilting angles before the slope failure.
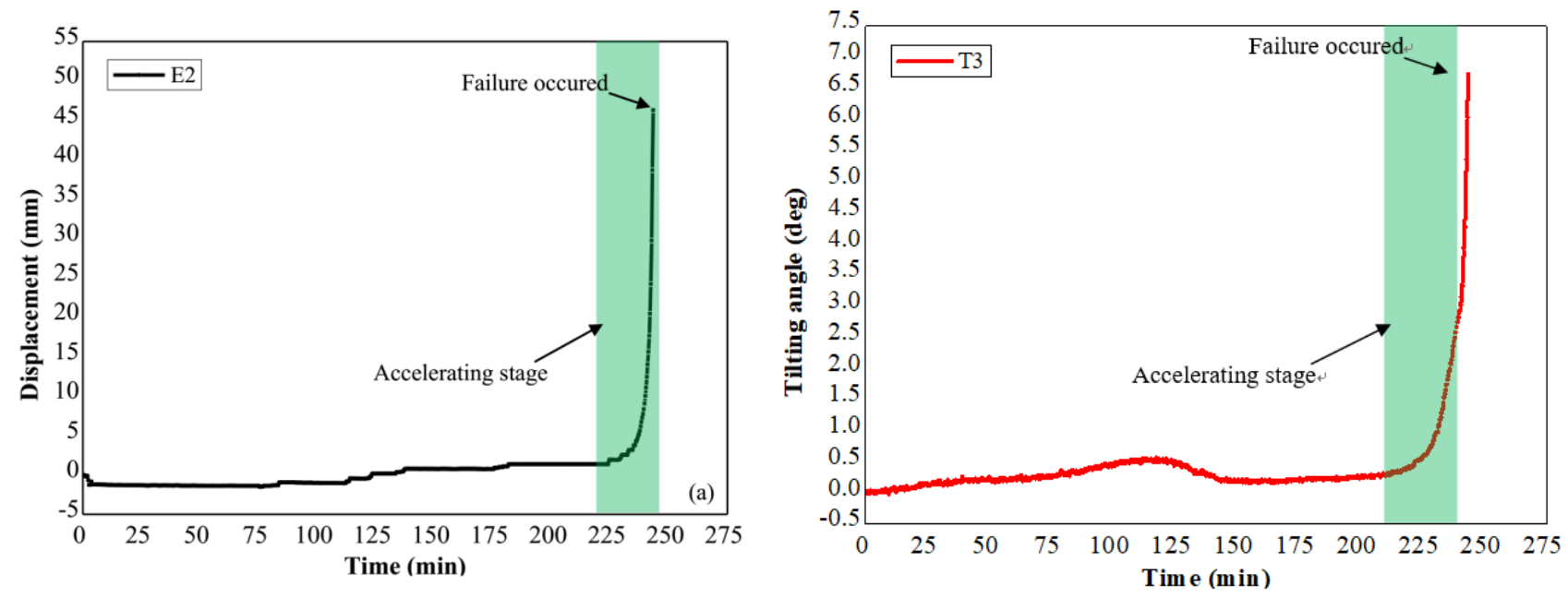

Figure 11. (a) Time history of the displacement at subsurface in Field Test 1, (b) time series of the tilting angle at the subsurface in Field Test 1.

Figure 12a shows the relation between the reciprocal displacement rate and time, which was obtained using the surface displacement measured by E2, while the time series of the reciprocal tilting rate is indicated in Figure 12b. Linear trends are implied in these two figures, and the slope failure time forecasted based on these trends using Equation (2) and Equation (3) is $242.6 \mathrm{~min}$ and $244.2 \mathrm{~min}$ respectively. The slight difference for the predicted failure time of the slope is caused by the variation of the data as shown in Figure 12a.
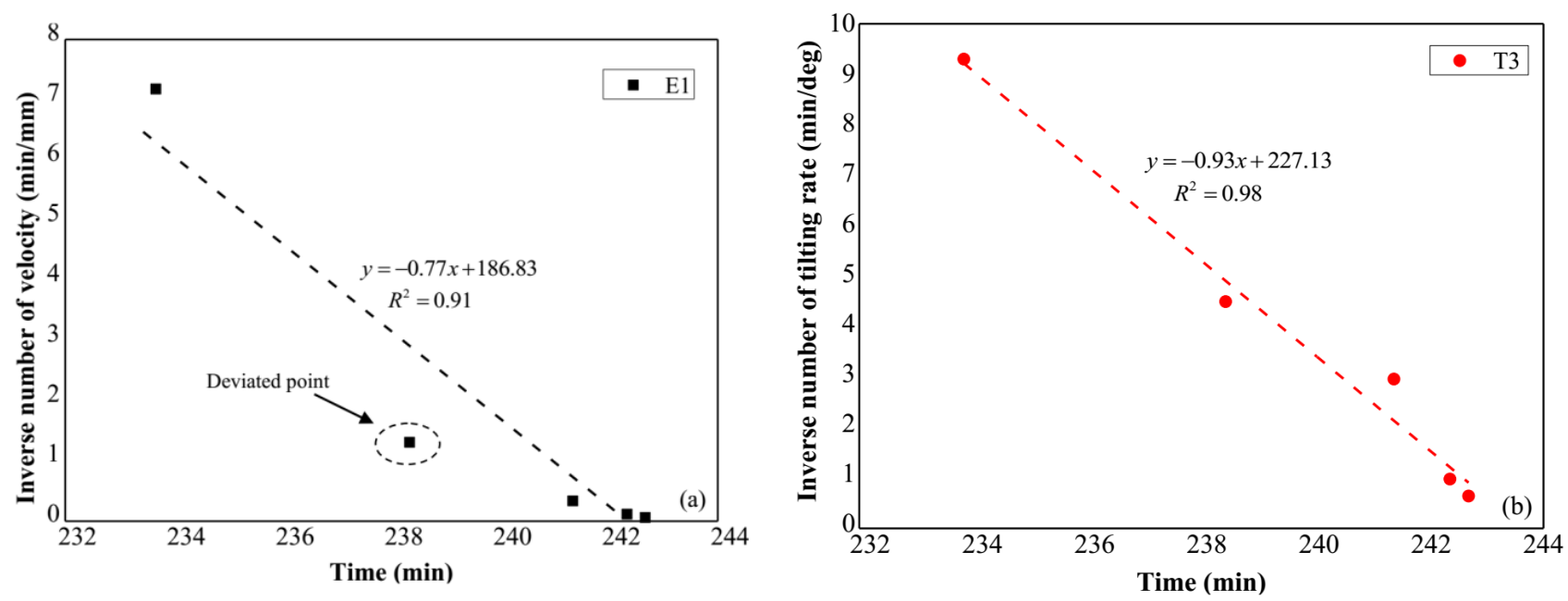

Figure 12. (a) Reciprocal displacement rate against time, (b) reciprocal tilting rate against time. 


\subsection{Results of Field Test 2}

The site of Field Test 2 is also located in Baise city, and the test conditions are similar as that in Field Test 1 with a different rainfall intensity of $27 \mathrm{~mm} / \mathrm{h}$. The failure occurred in the middle part of this slope, and the pre-failure behavior was recorded by the extensometer E4 and the tilt sensor T4 installed in this region as presented in Figure 5. The tilting angle and displacement of the failed part are presented in Figure 13a,b, respectively. As shown in Figure 13, the surface displacement and tilting increased sharply at the vicinity of $68 \mathrm{~min}$ until the slope failure occurred. A clear accelerating stage is also revealed in the time history of surface displacements and that of surface tilting, coinciding with the result indicated in other tests.
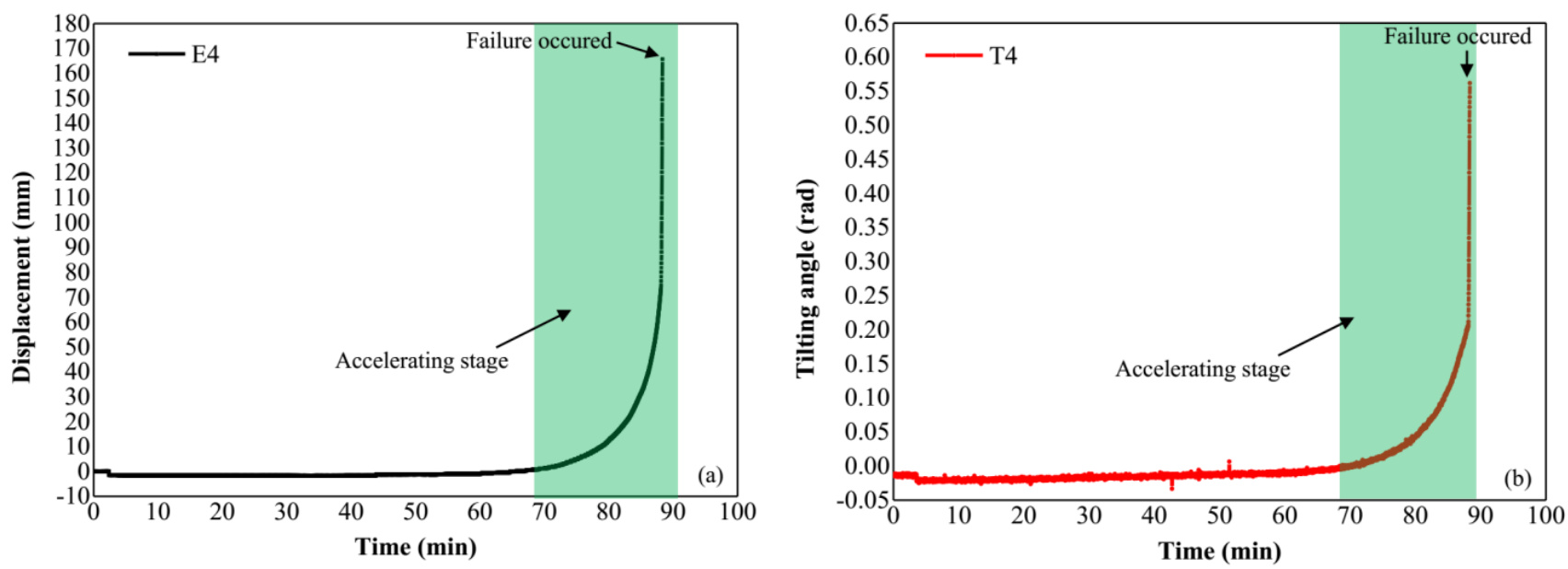

Figure 13. (a) Time history of the displacement at subsurface in Field Test 2, (b) time series of the tilting angle at the subsurface in Field Test 2.

The relationship between the inverse number of the displacement and tilting rate against time in the acceleration stage is implied in Figure 14a,b respectively. Linear relations between rates of surface deformation against time are indicated in these figures, and the predicted slope failure derived from the linear trends is $88.28 \mathrm{~min}$ and $88.20 \mathrm{~min}$ receptively, consistent with the actual slope failure time.
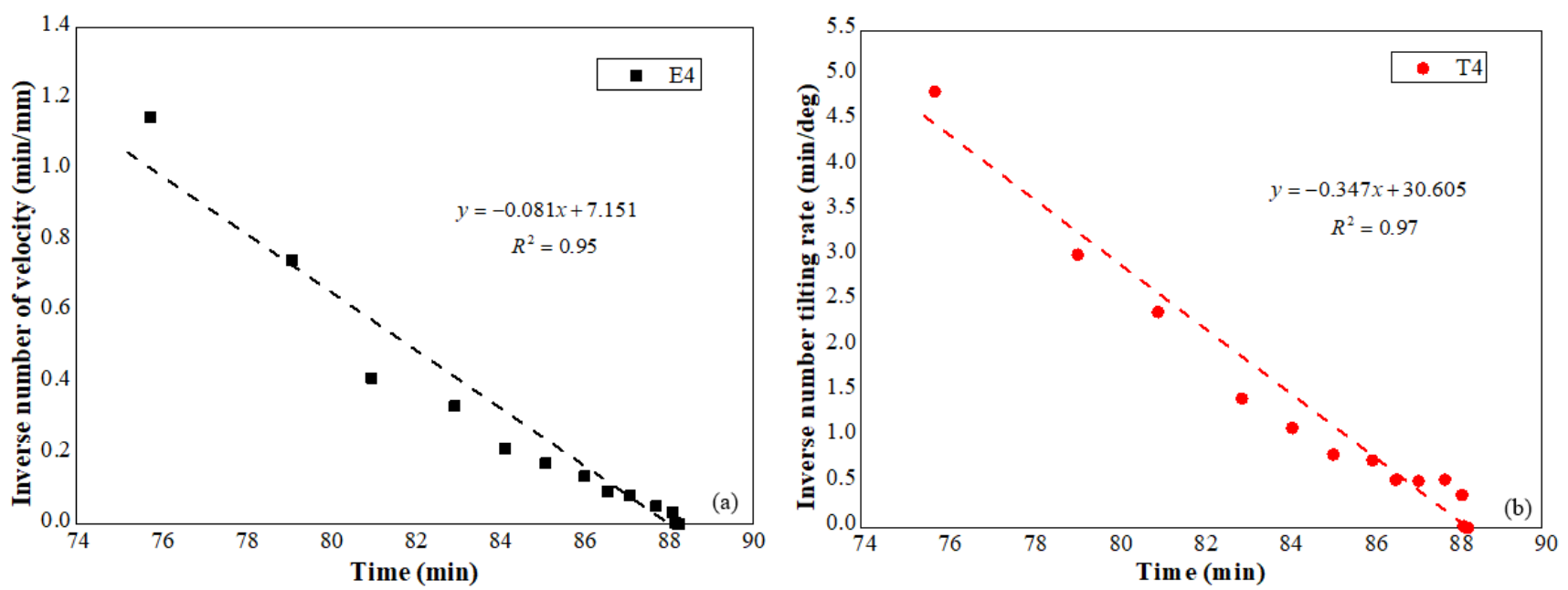

Figure 14. (a) Reciprocal displacement rate against time, (b) reciprocal tilting rate against time. 


\section{Discussion}

\subsection{A Comparison between Landslide Prediction Methods Based on Surface Displacements and Tilting}

Results of the laboratory and field tests indicate that the surface tilting increases synchronously with the increment of the displacement at slope surfaces. Additionally, the reciprocal rate of displacement and surface tilting against time were also presented in this study, and the first comparison between the landslide prediction method using surface tilting and that based on the time history of the surface displacement was carried out. In Model Test 1, failure of the slope with a pre-defined slip surface was triggered by rainfall infiltration. Consistent predicted failure time of the slope was achieved using the different landslide prediction method based on the tilting behavior and displacement of slope surface respectively. This result reveals that the landslide prediction methods based on the index of surface deformation are applicable for the slope with a pre-existed slip surface.

Compared with the test conditions in Model Test 1, a homogeneous slope model made of silica sand was exploited in Model Test 2 to investigate the reliability of the predicted slope failure time evaluated by Equations (2) and (3). The result in this test also indicate that the failure time of the slope estimated by the landslide forecasting method based on the surface displacement and tilting using Equations (2) and (3) are consistent, which are in good agreement with the real failure time of this slope.

Additionally, two field tests with varying rainfall intensity were also performed. As shown in Figures 11 and 13, accelerating stages of the surface displacement and tilting are indicated, coinciding with the results presented in the laboratory tests. Linear relationships between the rate of surface displacement and tilting against time are also revealed in Figures 12 and 14. Similar as the results indicated in the laboratory tests, the predicted slope failure time estimated by Equations (2) and (3) based on the linear relations between the rate of surface deformation and time is consistent with the real failure time.

Conclusively, either the traditional landslide prediction methods using the time history of surface displacement in the acceleration stage or the forecasting method of slope failure derived from the pre-failure slope surface tilting behavior can be used to obtain the slope failure time with high reliability, and differences causing by usage of these varying landslide prediction methods on the predicted failure time of slopes are negligible based on the results of laboratory tests and field tests.

\subsection{Possible Relationship between the Rate of Surface Displacement and Tilting}

The velocity of surface movements and the surface tilting rate have been considered as the significant indicator to assess the slope stability by many researchers in recent decades [26-28], and analogous landslide prediction methods using these indexes were also proposed as indicated in Equations (2) and (3). However, limited studies have been carried out to investigate relations between the velocity and tilting rate of the slope surface. In this study, the correlation between these indicators was explored and a possible mechanism for the slope failure was also discussed based on this correlation.

As shown in Figure 15, the correlation between the tilting rate and velocity of surface movements in the laboratory tests and field tests of this study is revealed. Linear relations between these two indicators are indicated with high coefficients of determination $\left(R^{2}\right)$. As a result, a possible expression for the relation between the rate of surface displacements and tilting is given as

$$
\frac{d s}{d t}=C \times \frac{d \theta}{d t}
$$

where $C$ is a coefficient of proportionality. $\frac{d s}{d t}$ and $\frac{d \theta}{d t}$ represent for the displacement rate and tilting rate, respectively. 

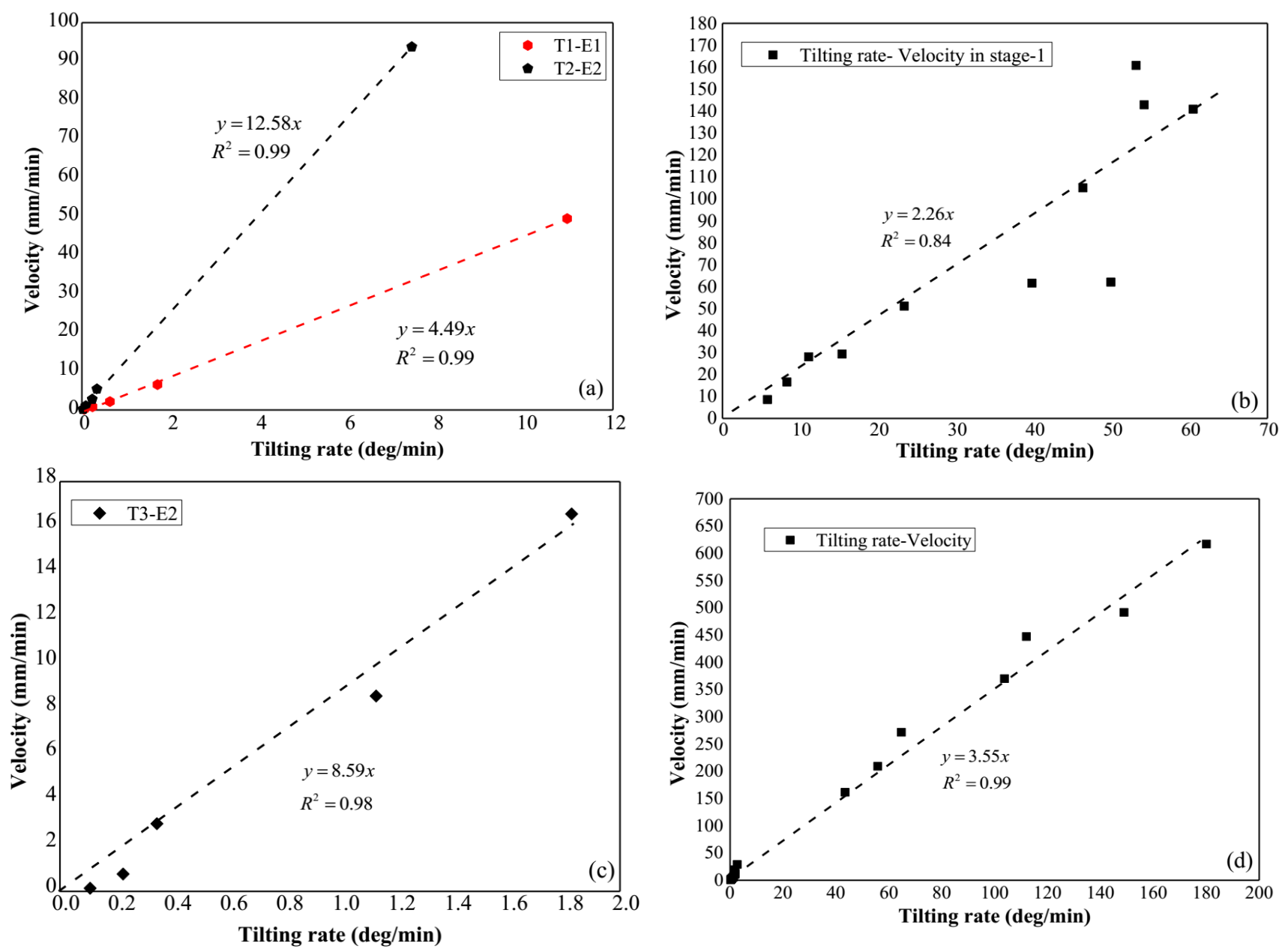

Figure 15. (a) Relationship between the tilting rate and the displacement rate in Model Test 1, (b) relationship between the tilting rate and the displacement rate in Model Test 2, (c) relationship between the tilting rate and the displacement rate in Field Test 1 , (d) relationship between the tilting rate and the displacement rate in Field Test 2.

In addition, it is obvious that if the inverse number of velocity in Equation (2) is substituted by Equation (4), the Equation (3) based on the surface tilting behavior can be achieved. This result provides the evidence to explain the similarity between Equations (2) and (3), and also gives the verification for the consistent estimated slope failure time obtained by different prediction methods as mentioned before.

Furthermore, the relations between the tilting rate and displacement rate in Model Test 1 with a pre-designed slip surface also reveal that the coefficients of these relations, which are 257.25 and 720.77 when the rate of surface displacements plot against the tilting rate using the unit radians instead of degrees as shown in Figure 16, approximate to the actual distances between centers of the slip surface and the location tilt sensors were installed with the values of $212 \mathrm{~mm}$ and $685 \mathrm{~mm}$ respectively.

This result implies that the deformation at the slope surface is mainly caused by the rotation of the sliding masses along the slip surface, and the internal deformation of the sliding mass is negligible. Considering this, we can infer that the possible mechanism for slope surface deformation in acceleration stage before slope failure is controlled by the reduction of shear resistance of the slip surface. Additionally, the result also indicates that the coefficient presented in Equation (4), $C$, is related to the geometry of the slip surface. 


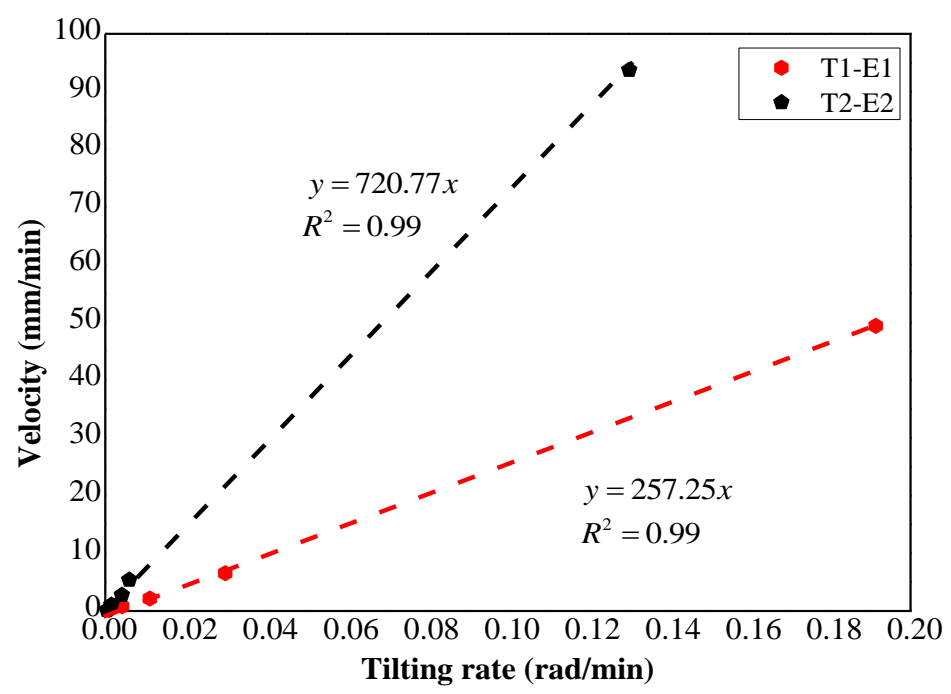

Figure 16. Tilting rate with unit $\mathrm{rad} / \mathrm{mm}$ against velocity in Model Test 1.

\section{Conclusions}

In this study, the first comparison between the landslide predicting methods based on the surface displacement and tilting was carried out by performing a series of the laboratory tests and a field test. In addition, the relationship between the tilting rate and displacement rate was also investigated. The major findings of this research can be drawn as follows:

1. The results of laboratory and field tests indicate that either the inverse velocity forecasting method or the landslide predicting method using the slope tilting measurement can be applied to evaluate the slope failure time, and the predicted failure time calculated by these two forecasting methods is consistent with the actual slope failure time.

2. Linear relations between the tilting rate and displacement rate was observed, and an expression for the linear relations was also proposed, in which the coefficient, $C$, is found to be controlled by the geometry of slope slip surfaces.

3. The relationship or similarity between the landslide prediction methods derived from the history of surface displacements and tilting as shown in Equations (2) and (3) was elucidated based on the test results.

4. Based on the results in Model Test 1, a possible mechanism for slope surface deformation was proposed, in which the acceleration stage of surface deformation is induced by the reduction of shear resistance along the slip surface.

Author Contributions: Conceptualization, J.X.; methodology, T.U.; investigation, J.X. and C.H.; data curation, J.T.; writing—original draft preparation, J.X.; writing-review and editing, C.H., Z.M. and J.T.; visualization, J.X. and C.H. All authors have read and agreed to the published version of the manuscript.

Funding: This research was funded by the Hunan Provincial Natural Science Foundation of China, grant number 2021JJ40764; Double First-Class university project of Central South University, grant number 13600-506010801; National Key R\&D Program of China, grant number 2018YFC1505403 and Fundamental Research Funds for the Central Universities of Central South University, grant number 2021zzts0782.

Institutional Review Board Statement: Not applicable.

Informed Consent Statement: Not applicable.

Data Availability Statement: Not applicable.

Acknowledgments: The authors would like to express their gratitude to the support of Hunan Provincial Natural Science Foundation of China (no. 2021JJ40764), Double First-Class university project of Central South University (no. 13600-506010801), National Key R\&D Program of China 
(grant no. 2018YFC1505403), and Fundamental Research Funds for the Central Universities of Central South University (2021zzts0782). We are grateful to academic editor Domenico Calcaterra and anonymous reviewers for their constructive comments which helped in improving our paper. Deep appreciation goes to assistant editor of Sensors journal for helpful comments and processing manuscript. In addition, the authors sincerely thank Shushen Xiong at Central South University and Zhixiong Zheng at China Construction Fifth Engineering Bureau CO.LTD for their useful suggestions.

Conflicts of Interest: The authors declare no conflict of interest.

\section{Appendix A}

The reciprocal rate of the displacement or tilting angle can be computed by the following equation,

$$
\left(\frac{d t}{d \Omega}\right)_{i+1}=\frac{t_{i+1}-t_{i}}{\Omega_{i+1}-\Omega_{i}} \quad(i=0,1, \ldots, n-1)
$$

where $\Omega$ represents the displacement or tilting angle, and $\Omega_{i+1}$ is the value of the variables at the time $t_{i+1} \cdot\left(\frac{d t}{d \Omega}\right)_{i+1}$ indicates the reciprocal rate of the variables at time $t_{i+1}$, and $n$ is the dimension of the data sets.

\section{References}

1. Klose, M.; Maurischat, P.; Dann, B. Landslide impacts in Germany: A historical and socioeconomic perspective. Landslides 2016, 13, 183-199. [CrossRef]

2. Petley, D.N. Global patterns of loss of life from landslides. Geology 2012, 40, 927-930. [CrossRef]

3. Froude, M.; Petley, D. Global fatal landslide occurrence from 2004 to 2016. Nat. Hazards Earth Syst. Sci. 2018, 18, $2161-2181$. [CrossRef]

4. Lee, K.; Suk, J.; Kim, H.; Jeong, S. Modeling of rainfall-induced landslides using a full-scale flume test. Landslides 2021, 18, 1153-1162. [CrossRef]

5. Yang, Z.; Wang, L.; Qiao, J.; Uchimura, T.; Wang, L. Application and verification of a multivariate real-time early warning method for rainfall-induced landslides: Implication for evolution of landslide-generated debris flows. Land-Slides 2020, 17, 2409-2419. [CrossRef]

6. Uchimura, T.; Towhata, I.; Wang, L.; Nishie, S.; Yamaguchi, H.; Seko, I.; Qiao, J. Precaution and early warning of surface failure of slopes by using tilt sensors. Soil Found. 2015, 55, 1086-1099. [CrossRef]

7. Intrieri, E.; Gigli, G. Landslide forecasting and factors influencing predictability. Nat. Hazards Earth Syst. Sci. 2016, 16, 2501-2510. [CrossRef]

8. Reichenbach, P.; Rossi, M.; Malamud, B.; Mihir, M.; Guzzetti, F. A review of statistically-based landslide susceptibility models. Earth-Sci. Rev. 2018, 180, 60-91. [CrossRef]

9. Dixon, N.; Smith, A.; Flint, J.A.; Khanna, R.; Clark, B.; Andjelkovic, M. An acoustic emission landslide early warning system for communities in low-income and middle-income countries. Landslides 2018, 15, 1631-1644. [CrossRef]

10. Xie, J.; Uchimura, T.; Wang, G.; Selvarajah, H.; Maqsood, Z.; Shen, Q.; Mei, G.; Qiao, S. Predicting the sliding behaviour of rotational landslides based on the tilting measurement of the slope surface. Eng. Geol. 2020, 269, 105554. [CrossRef]

11. Wang, S.; Idinger, G.; Wu, W. Centrifuge modelling of rainfall-induced slope failure in variably saturated soil. Acta Geotech. 2021, 16, 2899-2916. [CrossRef]

12. Lu, M.; Zhang, J.; Zheng, J.; Yu, Y. Assessing annual probability of rainfall-induced slope failure through a mechanics-based model. Acta Geotech. 2021, 1-16. [CrossRef]

13. Rahardjo, H.; Nistor, M.M.; Gofar, N.; Satyanaga, A.; Xiaosheng, Q.; Chui Yee, S.I. Spatial distribution, variation and trend of five-day antecedent rainfall in Singapore. Georisk Assess. Manag. Risk Eng. Syst. Geohazards 2020, 14, 177-191. [CrossRef]

14. Chae, B.G.; Kim, M.I. Suggestion of a method for landslide early warning using the change in the volumetric water content gradient due to rainfall infiltration. Environ. Earth Sci. 2012, 66, 1973-1986. [CrossRef]

15. Wu, L.Z.; Huang, R.Q.; Xu, Q.; Zhang, L.M.; Li, H.L. Analysis of physical testing of rainfall-induced soil slope failures. Environ. Earth Sci. 2015, 73, 8519-8531. [CrossRef]

16. Keefer, D.K.; Wilson, R.C.; Mark, R.K.; Brabb, E.E.; Brown, W.; Ellen, S.D.; Harp, E.L.; Wieczorek, G.F.; Alger, C.S.; Zatkin, R.S. Real-time landslide warning during heavy rainfall. Science 1987, 238, 921-925. [CrossRef] [PubMed]

17. Chen, M.; Jiang, Q.H. An early warning system integrating time-of-failure analysis and alert procedure for slope failures. Eng. Geol. 2020, 272, 105629. [CrossRef]

18. John, E.; Alessio, F.; Lyesse, L. Early warning thresholds for partially saturated slopes in volcanic ashes. Comput. Geotech. 2013, 49, 79-89. 
19. Petley, D.N.; Mantovani, F.; Bulmer, M.H.; Zannoni, A. The use of surface monitoring data for the interpretation of landslide movement patterns. Geomorphology 2005, 66, 133-147. [CrossRef]

20. Mufundirwa, A.; Fujii, Y.; Kodama, J. A new practical method for prediction of geomechanical failure-time. International. J. Rock Mech. Min. Sci. 2010, 47, 1079-1090. [CrossRef]

21. Hao, S.W.; Liu, C.; Lu, C.S.; Elsworth, D. A relation to predict the failure of materials and potential application to volcanic eruptions and landslides. Sci. Rep. 2016, 6, 1-7. [CrossRef] [PubMed]

22. Fukuzono, T. A New Method for Predicting the Failure Time of Slopes. In Proceedings of the 4th International Conference \& Field Workshop on Landslides, Tokyo, Japan, 23-31 August 1985; pp. 145-150.

23. Voight, B. A Relation to Describe Rate-Dependent Material Failure. Science 1989, 243, 200-203. [CrossRef] [PubMed]

24. Tommaso, C.; Paolo, F.; Intrieri, E.; Hakki, K.; Nicola, C. Integration of ground-based radar and satellite InSAR data for the analysis of an unexpected slope failure in an open-pit mine. Eng. Geol. 2018, 235, 39-52.

25. Abraham, M.T.; Satyam, N.; Pradhan, B.; Alamri, A.M. IoT-based geotechnical monitoring of unstable slopes for land-slide early warning in the Darjeeling Himalayas. Sensors 2020, 20, 2611. [CrossRef] [PubMed]

26. Federico, A.; Popescu, M.; Murianni, A. Temporal prediction of landslide occurrence: A possibility or a challenge? Ital. J. Eng. Geol. Environ. 2015, 1, 41-60.

27. Stähli, M.; Sättele, M.; Huggel, C.; McArdell, B.W.; Lehmann, P.; Van, H.A.; Berne, A.; Schleiss, M.; Ferrari, A.; Kos, A.; et al. Monitoring and prediction in early warning systems for rapid mass movements. Nat. Hazards Earth Syst. Sci. 2015, 15, 905-917. [CrossRef]

28. Xie, J.R.; Uchimura, T.; Wang, G.H.; Shen, Q.; Maqsood, Z.; Xie, C.R.; Liu, J.P.; Lei, W.K.; Tao, S.N.; Chen, P.; et al. A new prediction method for the occurrence of landslides based on the time history of tilting of the slope surface. Landslides 2019, 17, 301-312. [CrossRef] 